\title{
0 pintar o si-mesmo de Van Gogh: uma perspectiva winnicottiana
}

\author{
Van Gogh's painting the self: a winnicottian perspective
}

\section{Eduarda Rosa de Oliveira e Mariana Steiger Ungaretti ${ }^{2}$}

Resumo: A arte de Vincent possibilitou o exercício do seu potencial de vir-a-ser, do croqui até o pintar o si-mesmo. O propósito deste artigo é realizar uma revisão narrativa de literatura explorando, a partir da teoria desenvolvida por Winnicott, alguns elementos da trajetória criativa de Vincent Van Gogh. Para a construção deste trabalho foram selecionados artigos e teses na língua portuguesa nas seguintes bases de dados: IndexPsi, catálogo de teses e dissertações da CAPES, BVS-Psi, PePSIC e Google Acadêmico. Além de materiais teóricos clássicos da psicanálise winnicottiana, também foram utilizadas cartas trocadas entre o pintor e o seu irmão mais novo Theo. O entendimento da arquitetura familiar - e, especificamente, do seu irmão natimorto homônimo - viabilizou a compreensão do desenvolvimento de Vincent e da sua potência criativa. Gestado na morte e a partir dela, Van Gogh dedicou toda sua capacidade de vida, de morte e de criação não somente para pintar suas telas, mas para pintar o si-mesmo.

Palavras-chave: Van Gogh; Winnicott; Criatividade.
Abstract: Vincent's art enabled the exercise of his potential to become himself, from sketching to painting the self. The purpose of this article is to conduct a narrative literature review exploring, from the theory developed by Winnicott, some elements of Vincent Van Gogh's creative trajectory. For the construction of this work we selected articles and theses in portuguese language from the following databases: IndexPsi, catalog of theses and dissertations from CAPES, BVS-Psi, PePSIC and Google Acadêmico. Besides classic theoretical materials from winnicottian psychoanalysis, letters exchanged between the painter and his younger brother Theo were also used. The understanding of the family architecture and, specifically, of his stillborn brother of the same name - made it possible to understand Vincent's development and his creative power. Born in and from death, Van Gogh dedicated all his capacity for life, death, and creation not only to paint his canvases, but to paint himself.

Keywords: Van Gogh; Winnicott; Creativity.

\footnotetext{
1 Graduanda em Psicologia na Faculdade Meridional (IMED). Bolsista de iniciação científica do Núcleo de Infância e Família (NUDIF/UFRGS).E-mail: deoliveira.eduarda.r@gmail.com

2 Psicóloga. Psicanalista. Mestre em Psicologia Clínica pela Pontifícia Universidade Católica do Rio Grande do Sul (PUCRS). Professora do Curso de Psicologia na Faculdade Meridional (IMED). E-mail: marianasungaretti@gmail.com
} 


\section{Introdução}

Não há nada mais expressivo do que começar a falar de Vincent pelo seu fim. Van Gogh, filho do pastor holandês Theodorus Van Gogh e de Anna Cornelia, nasceu e morreu em 30 de março de 1852. Exatamente um ano depois, nasce o segundo filho, o futuro pintor, que recebe o mesmo nome do falecido irmão. De acordo com Naifeh e Smith (2011), nas gerações anteriores a morte de uma criança pequena, especificamente de um natimorto, quase não era citada. Muitas vezes esse bebê sequer recebia algum nome.

Pela primeira vez no local onde moravam foi aberto um túmulo para um natimorto e feito em um cemitério próximo à igreja de Zundert. Na lápide estava entalhada a frase bíblica "vinde a mim as criancinhas" e o nome completo do bebê — não somente o nome dos pais como era comum para a época (Naifeh \& Smith, 2011). A mãe enlutada levava o pequeno Vincent todos os domingos para visitar e enfeitar a morada do seu irmão (Britto, 2018). Mais do que isso, o homônimo morto se fazia presente na moradia dos Van Gogh, pois o túmulo era anexo à propriedade onde residiam (Britto, 2018; Maesso, 2017). 0 heterônimo sobrevivente sentia diariamente a sua identidade escrita em uma lápide. Vincent era homônimo pelo nome e heterônimo como a própria extensão do irmão morto.

A partir da teoria winnicottiana é possível explanar como a arquitetura familiar impactou o desenvolvimento do cerne do irmão sobrevivente. Observa-se um ambiente incapaz de perceber sua singularidade, de modo que para dar conta da realidade evidencia certa submissão aos objetos primários. Em virtude de tanta intensidade, interroga-se acerca de um possível prejúzzo na integração e desenvolvimento egóico de Vincent.

\section{Método}

0 presente artigo é de cunho qualitativo e trata-se de uma revisão narrativa de literatura sobre a trajetória pessoal e profissional de Van Gogh à luz da teoria winnicottiana. A pesquisa qualitativa é vinculada ao estudo de estruturas teóricas que possibilitam elucidar os fenômenos e contextos associados a uma temática (Creswell, 2014). Consoante Gil (2019), a revisão narrativa corresponde à discussão de conceitos, a partir de materiais já elaborados para descrever, integrar e interpretar um conjunto de elementos.

Para a realização dessa revisão foram selecionados artigos e teses em português nas seguintes bases de dados: IndexPsi, catálogo de teses e dissertaçōes da CAPES, BVS-Psi, PePSIC e Google Acadêmico. Os critérios de inclusão utilizados nessa pesquisa foram publicações em português e com conteúdo integral disponível para acesso eletrônico. Além dos documentos já mencionados, foram utilizadas cartas escritas pelo por Vincent e Theo Van Gogh, assim como textos e livros clássicos vinculados à teoria winnicottiana e a identidade artística do pintor.

\section{O croqui do si mesmo}

A mãe de Vincent, Anna, cresceu em um ambiente com uma visão pessimista, onde qual quer pequena felicidade era precedente a uma catástrofe (Britto, 2018). Mesmo no seu belo casamento ficava excessivamente triste por recordar de algum parente que não tinha comparecido (Naifeh \& Smith, 2011). Quando seu marido ia fazer alguma atividade fora de casa, ficava excessivamente preocupada com a ideia de o mesmo morrer (Naifeh \& Smith,
2011). De acordo com os autores, para ela as decepções nunca parariam e somente os tolos aspirariam muito da vida.

Anna era vista como uma mulher muito rígida, pessimista e com tendência à melancolia (Britto, 2018). Sua felicidade era sempre ligada à tentativa de manutenção da ordem. Em virtude disso, quando algo fugia de seu controle, punha-se a limpar avidamente os móveis (Naifeh \& Smith, 2011). 0 pequeno Vincent justamente atuava como uma ameaça à normatização da mãe. Certa vez, em uma reunião familiar um dos parentes citou queVincent era briguento e que "nunca prestava a menor atenção ao que o mundo chama de ordem" (Naifeh \& Smith, 2011, p. 62).

0 pai de Vincent, Theodorus, era percebido como o representante direto de Deus na terra. De acordo com Haziot (2007), a família Van Gogh tinha tradição em funções religiosas, pois vários membros eram pastores protestantes, assim como Theodorus. Apesar de receber um salário pequeno, a família aparentava pertencer à elite, visto que a igreja viabilizou inúmeros serventes (Naifeh \& Smith, 2011). Nada mais justo, afinal, tinha a incumbência de propagar a fé protestante para que não ocorresse a hegemonia da religião católica em um território que estava sendo tão disputado.

Voz do Pai no culto, voz do pai em casa. Como um verdadeiro exemplar divino do século XIX, Dorus também demonstrava a ira de Deus. Quando um cordeiro faltava ao culto dominical, o pastor "vociferava contra aquela escória que questionava a sua autoridade" (Naifeh \& Smith, 2011, p. 78). A mesma dissidência proibida ao rebanho da casa do Senhor também não era permitida no lar dos Van Gogh. Por conseguinte, Vincent aprendeu que desapontar o pai era desapontar Deus (Naifeh \& Smith, 2011). Ao mesmo tempo que Dorus era um pai gentil e apoiador, era repressivo e expressava o quanto os filhos incomodavam — especialmenteVincent (Naifeh \& Smith, 2011). Para Dorus, Vincent era 0 tormento da vida dos pais e escolhia de forma minuciosa a maneira de criar dificuldades (Naifeh \& Smith, 2011).

Cachos ruivos, olhos claros, olhar penetrante e vazio. 0 pequeno Vincent era muito parecido com a mãe não somente em suas características físicas, mas também na visão perante a vida, aos outros e a si mesmo. Como um reflexo da própria infância, ela apresentou ao filho várias atividades, como aulas de canto e de piano (Dos Santos, 2018). A mais significativa entre elas era 0 trabalho artístico. Quando pequena, aprendeu a desenhar e a pintar com aquarela (Naifeh \& Smith, 2011). A temática predileta dela seria um dos elementos centrais da obra vangoguiana. A mãe fornecia seus trabalhos com flores e buquês decorativos para o filho reproduzir e pintar (Haziot, 2007). De acordo com Dos Santos (2018), em uma ocasião, quando criança, Vincent fez um desenho que não gostou. Não tolerando a frustração, amassou, jogou fora e não fez mais nenhum trabalho à mão livre enquanto moravam na mesma cidade. Alguns anos depois, quando adulto, jogou fora todos os croquis que havia produzido na infância, alegando que eram somente alguns rabiscos (Naifeh \& Smith, 2011). Vincent e Anna compartilhavam não somente da mesma paixão por flores, mas também da mesma severidade consigo.

Anna e Theodorus tiveram mais cinco filhos (Naifeh \& Smith, 2011). Dois nomes derivaram do pai e dois da mãe, já o nome dos homônimos é transgeracional. Além de Vincent ser o nome do tio e avô paterno, Willem faz referência ao outro avô (Haziot, 2007). Essa tradição teve continuidade com Theo ao nomear o seu filho também como Vincent. Apesar de ter tantos irmãos para brincar, o futuro pintor preferia ficar isolado. De acordo com Haziot (2007), a conduta e a visão de um jovem excêntrico envergonhavam uma família tão relevante na pequena e tradicional cidade de Zundert. Na medida em que se 
distanciava era marginalizado pela família e pela sociedade. Talvez o único esboço de um relacionamento mais saudável tenha sido com o seu irmão Theo.

Com vinte e sete anos, Vincent decide dedicar-se à pintura (Dos Santos, 2018). Toda a sua vasta obra foi desenvolvida em nove anos. Apesar dos inúmeros esforços para conseguir impressionista dinheiro, Vincent vivia na miséria (Van Gogh, 2020). 0 pouco tostão que tinha vinha de seu irmão Theo, que mal conseguia cobrir todas as despesas (Van Gogh, 1958). 0 irmão não era somente o seu mantenedor. Se Vincent vivia para pintar, Theo vivia para proteger e divulgar uma arte e uma história que eram maiores do que eles. Em uma carta, Theo Van Gogh (1888/1990) responde a Vincent sobre a questão financeira.

Você fala sobre o dinheiro que me deve e que deseja me devolver. Eu não sei nada disso. . . Devo trabalhar para ganhar dinheiro . . . podemos aguentar por algum tempo . . Você não sabe como me entristece quando diz que terá trabalhado tanto que sentirá que não viveu. Em primeiro lugar, acredito que não seja verdade, porque você está de fato vivendo, e da mesma forma que grandes homens e nobres. (Fragmento retirado carta 713)

0 ciclo de internações de Vincent começou em dezembro de 1888 quando, diante de suas intensidades, após perseguir o seu amado e odiado amigo Gauguin, cortou e levou a sua orelha para uma mulher no bordel ( $\mathrm{Ha}$ ziot, 2007). 0 sangramento era tanto que foi levado ao hospital, mas acabou ficando mais devido aos seus episódios agressivos (Dos Santos, 2018). Um mês após a alta, ele decide se internar voluntariamente. Alguns meses depois, em maio de 1890, vive uma fase rara de equilíbrio ao mudar-se para Auvers (Dos Santos, 2018). Essa bonança permaneceu até o mês de julho, quando Vincent teve um ferimento causado por uma bala. Theo chegou desesperado para ver o irmão, mas o encontrou sentado fumando em seu quarto. Consoante Naifeh e Smith (2011), apesar da suposta estabilidade, morreu dois dias depois em paz, nos braços do seu tão amado Theo, no aconchego de um quartinho que dividiam, assim como na infância. Suas últimas palavras foram "é assim que quero morrer" (Naifeh \& Smith, 2011, p. 977).

0 pouco tempo de vida que restou a Theo foi dedicado a fornecer dignidade ao irmão e a não permitir que Vincent fosse esquecido (Naifeh \& Smith, 2011). 0 vínculo de Theo era tanto que no mesmo ano começou a desenvolver uma série de problemas de saúde, depressão, paralisia e esquizofrenia (Haziot, 2007). Ele morreu em janeiro de 1891 e foi enterrado ao lado de Vincent, em Auvers (Haziot, 2007). Jo, viúva de Theo, continuou compartilhando as histórias e as obras dos irmãos Van Gogh (Dos Santos, 2018). Posteriormente quando chegou o momento, o seu filho, o terceiro homônimo Vincent, continuou a missão (Naifeh \& Smith, 2011).

\section{O pintar o si-mesmo}

A teoria winnicottiana, alicerçada na dinâmica da segunda tópica de Freud, considera que o ser humano possui um cerne inato que, caso 0 ambiente seja facilitador, torna-se desenvolvido (Winnicott, 2013). Consoante o autor, essa complexização é organizada em três etapas: dependência absoluta, dependência relativa e independência. Para que esse amadurecimento ocorra 0 bebê precisa mais do que um mediador (Winnicott, 1975). Necessita de alguém que seja o próprio ambiente, que junte os seus fractais para, posteriormente, o si-mesmo ser constituído.

Na primeira fase o bebê é fragmentado, descontinuado. Ele é todo potencial de vir-a-ser, pois não existe a diferenciação entre eu-não eu e dentro-fora (Belo \& Scodeler, 2013; Galvan, 2013). Com o propósito dos fractais serem integrados e das fronteiras serem estabelecidas, é necessária uma continuidade-de-ser, onde a mãe suficientemente boa atua como ego auxiliar do filho (Fulgencio, 2018; Riter, 2018). 0 posicionamento do ambiente não necessariamente faz referência à mãe biológica, mas sim à figura que ocupa a função da maternagem (Winnicott, 2020). A mãe suficientemente boa é o objeto que oferece sustentação, contenção e amor para que o bebê acesse a sua capacidade criativa e para que suporte as angústias inerentes ao amadurecimento do cerne.

Segundo Winnicott (2020), a mãe-ambiente é aquela que espelha 0 infante para que ele seja percebido na sua singularidade. Se a mãe somente olha para 0 bebê, não permite que ele veja o próprio reflexo. Todavia, se 0 percebe, acaba por refletir todo o potencial do vir-a-ser, toda a capacidade criativa e inventiva que viabiliza que o bebê construa 0 si-mesmo (Leão, 2011). Para que esse processo ocorra, é necessário que o objeto primordial tenha um funcionamento mais regressivo, pois deve estar fusionado com 0 bebê (Medeiros \& Passos, 2018; Santos, 2019).

À vista disso, a mãe suficientemente boa faz um desinvestimento exogâmico e atinge um estado de devoção para atender as demandas alimentares — físicas e psíquicas — do filho (Medeiros \& Passos, 2018; Neto, 2018; Serralha, 2019). Dessa forma torna-se responsável por nutrir a onipotência do bebê (Neto, 2018). 0 absolutismo daquele vir-a-ser é um movimento no espaço-tempo que proporciona o fantasiar. Essa ilusão simbólica faz com que o bebê acredite que tudo é fruto da sua própria criação (Winnicott, 1975a). A capacidade criativa atua como força motriz para a construção do si-mesmo. Dessa forma, a constituição da identidade torna-se uma das primeiras manifestações criativas da criança. Em virtude de a criatividade não ser vinculada somente a um campo sublimatório e sim à criação do verdadeiro si-mesmo, torna-se a própria manifestação da vida.

Para que o cerne da criança se torne cada vez mais complexo, é necessária uma fase que viabilize a transição do mundo subjetivo para o objetivo (Paiva, 2020). A fase da dependência relativa é associada à quando, paulatinamente, a figura primordial retorna o seu investimento ao mundo endogâmico (Paiva, 2020). À medida que a mãe diminui o estado regressivo devocional, o bebê diminui a sua condição de dependência. Para que esse processo ocorra, conforme Galvan (2013), o ambiente deve gerar pequenas descontinuidades de forma a introduzir normatizações sociais e culturais. Esses traumas benignos - constituídos por falhas e reparações — são constitutivos e permitem que o bebê desenvolva ferramentas para lidar com o fracasso ambiental, que é inerente à existência humana (Maggi, 2020; Paiva, 2020).

Apesar de estar em maior contato com o princípio da realidade e, consequentemente, com a sua sujeição, o infante ainda precisa de uma mediação para se adaptar a esse mundo que cada vez se torna mais objetivo (Medeiros \& Passos, 2018). Um mediador que não seja, diretamente, um prolongamento da mãe, mas sim um representante. Consoante Winnicott (1993) o objeto transicional é esse intermediário entre o cerne e o mundo exterior. Para continuar com a busca e o croqui do si-mesmo, o bebê precisa exercitar a sua potência criativa. Com a diminuição gradual da onipotência, 0 espaço transicional ganha forma (Paiva, 2020). Esse locus faz com que sejam 
estabelecidas fronteiras um pouco mais definidas entre o interno-externo e entre o eu-não eu.

Segundo Winnicott (2013), há diferentes espectros do falso si-mesmo. Para 0 autor, a versão mais amena é relacionada a uma pequena dosagem constitutiva que permite o reajuste da ideia de onipotência sem perder a capacidade criativa. A fase da independência é caracterizada pela integração dos fractais do si-mesmo (Fulgencio, 2018). 0 cerne mais amadurecido permite que 0 indivíduo substitua 0 cuidado das figuras primordiais pelo cuidar-de-si-mesmo (Santos, 2019). Para o autor, apesar de existir autonomia, o sujeito saudável não é um eremita, mas relaciona-se de forma interdependente com 0 ambiente de forma a não perder suas características individuais.

Mesmo ainda estando no útero, o ser humano já é capaz de ter experiências, de armazenar memórias e de organizar mecanismos defensivos contra possíveis traumas (Borges, 2017; Paiva, 2020; Santos, 2019). De acordo com Leão (2011),os traumas podem ser entendidos a partir de falhas ambientais que causaram submissão do bebêà realidade. Pode-se pensar queVincent foi exposto a essas marcas mnêmicas invasivas antes mesmo de nascer. Quando era pequeno adorava literatura. De todos os contos que leu, teve preferência por História da Mãe. Além de ter decorado, adorava recitar para outras crianças. Nesse conto de Hans Cristhian Andersen a mãe,

Passa por várias provas, entregando seus olhos, seus cabelos, o calor do seu corpo, chegando, enfim, a arriscar a sua própria vida, pelo amor ao filho doente, para tê-lo de volta. Em uma decisão altruísta, contudo, entrega o filho aos desígnios de Deus, na esperança de que ele possa ser feliz na outra vida (Naifeh \& Smith, 2011, p. 31).
Levando em conta o contexto, é possível ponderar que após o nascimento do filho, Anna não espelhava o vivo, mas sim o homônimo morto. Vincent era o simbolismo do luto e do mortífero. Talvez até mesmo do ressurreto. "Vinde a mim as criancinhas" escreveram os pais de Vincent no túmulo do primeiro homônimo (Naifeh \& Smith, 2011). Por que escrever o plural na lápide singular? Van Gogh era o heterônimo, a simples continuidade de um filho idealizado morto. Os pais, diante das próprias intensidades e do luto, possivelmente não o perceberam na sua singularidade. Por conseguinte, 0 ambiente não foi suficientemente bom, visto que as figuras primordiais não refletiam todo potencial de vir-a-ser, e sim as próprias demandas. Dois anos antes de morrer, em uma carta enviada para o irmão, Van Gogh (1885/1991) descreve a sua figura no auto retrato como sendo magra e pálida como um fantasma (Figura 3).

Consoante Winnicott (2013), quando 0 ambiente nutre de forma complementar a onipotência infantil, o verdadeiro si-mesmo começa a ganhar vida. Como Vincent foi exposto às falhas ambientais prematuras, as figuras primordiais possivelmente não foram capazes ou não conseguiram fazer essa complementação. Considerando que Anna estava mais direcionada para 0 exogâmico, provavelmente o bebê tornou-se assujeitado ao ambiente externo.

Uma via plausível de investigação sobre a sujeição de Vincent ao externo pode ser realizada a partir dos seus autorretratos. De forma preponderante, ele mostrava-se indiferenciado do fundo (Maia, 2018). Em muitas telas o seu tom de pele era semelhante ao do fundo (Figura 1). Em outras, a tonalidade da roupa era quase um prolongamento do fundo (Figura 2). A posição que Vincent ocupava nas suas telas e na sua vida não era de sujeito, e sim de sujeição ao externo.

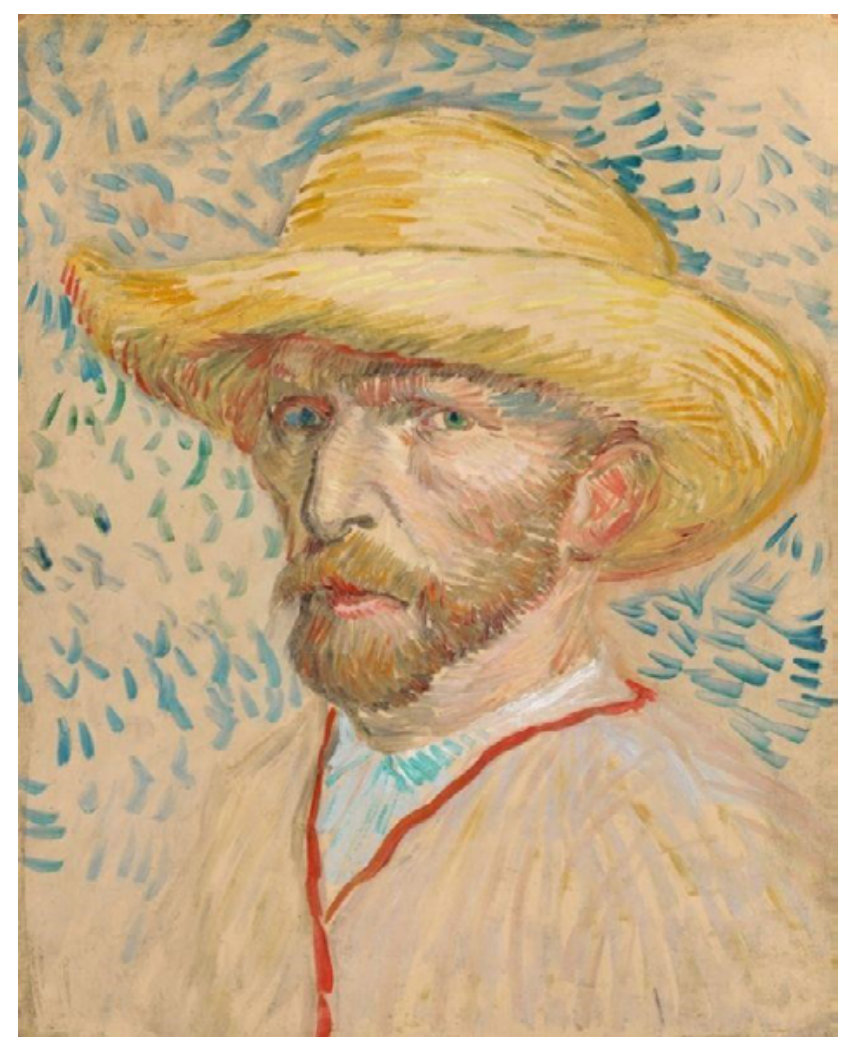

Figura 1. SEQ Figura $\backslash^{*} A R A B I C$ 1. Van Gogh, V. (1887) Self-portrait with straw hat [óleo sobre tela]. Foundation E.G. Bührle, Zurich. Extraído de http://www.vggallery.com/painting/p_0469.htm 


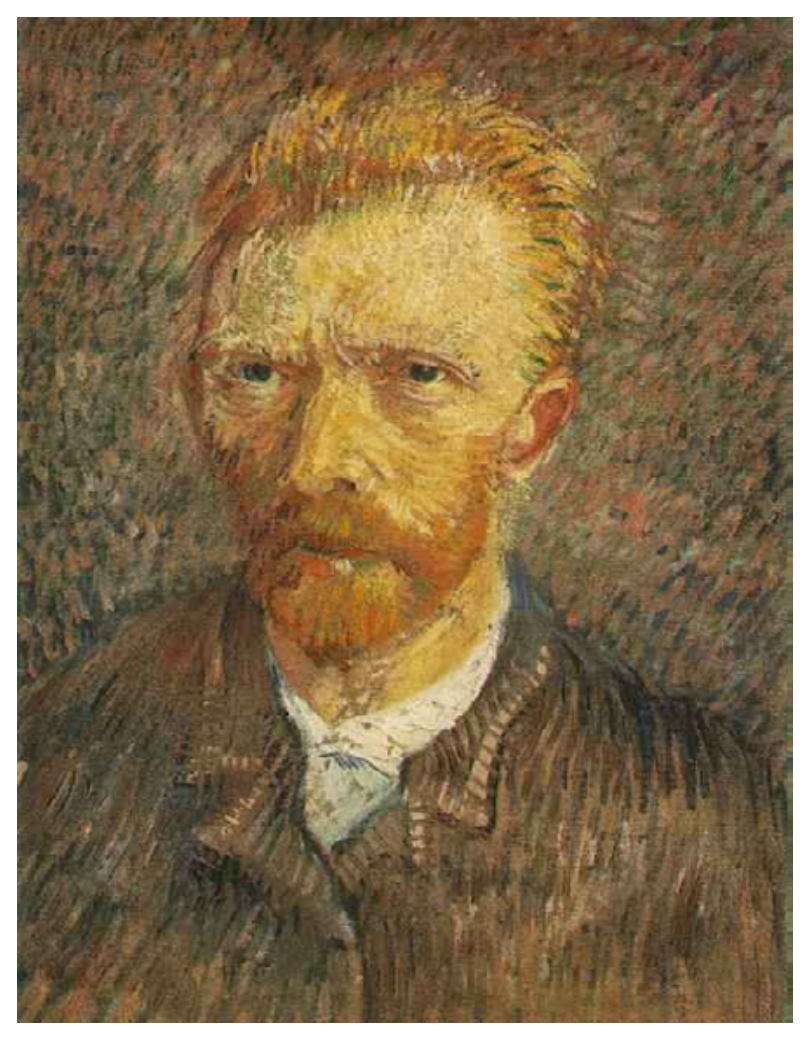

Figura 2. Van Gogh, V. (1887) Self-portrait [óleo sobre tela]. Foundation E.G. Bührle, Zurich.

Extraído de http://www.vggallery.com/painting/p_0366.htm

Em 1888 ele pintou um dos poucos autorretratos onde é possível distingui-lo do fundo (Figura 3). Em geral nos anteriores aparecia somente a sua imagem do tronco para cima, mas nesse vemos ele pintando, onde existe quase uma unificação entre a paleta e a mão. Apesar do uso de cores mais suaves e vivas, em uma carta para a sua irmã ele descreveu o seu autorretrato, em terceira pessoa, da seguinte forma:

Uma blusa azul de camponês feita de linho grosseiro e a palheta com amarelo limão, vermelho, verde-malaquita, azul-cobalto, em resumo, todas as cores na palheta exceto 0 alaranjado da barba. A figura em contraste à parede branca acinzentada. Você dirá que parece, por exemplo, a face da morte (Van Gogh, 1958, p. 437).

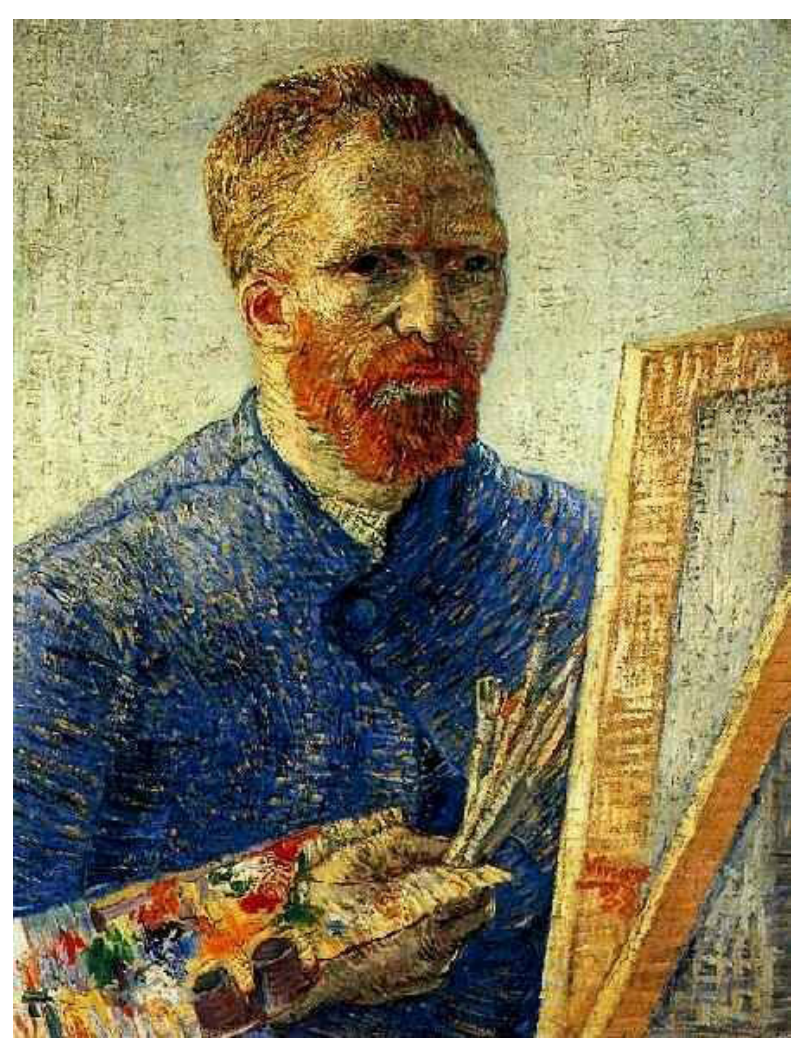

Figura 3. Van Gogh, V. (1888) Self-Portrait in Front of the Easel [Óleo sobre tela]. Van Gogh Museum, Amsterdam.

Extraído de http://www.vggallery.com/painting/p_0522.htm 
Possivelmente a continuidade-de-ser de Vincent foi interferida de forma tão prematura que comprometeu, em diversos níveis, a integração do ego e a constituição do si-mesmo (Paiva, 2020; Riter, 2018). 0 falso si-mesmo é caracterizado por "não ter meios de experimentar a vida ou de sentir-se real" (Winnicott,2000, p. 395). Há o predomínio de sentimentos vinculados à irrealidade e ao estranhamento de si, como é possível verificar em uma carta que Vincent enviou para Theo: "enfim, seja como for, eu quero ir adiante a qualquer custo, quero ser eu mesmo" (Van Gogh, 1886/2020, p. 174). Para Winnicott (2013), o falso si-mesmo tem, entre outras funções, a finalidade defensiva de ocultar e proteger o verdadeiro para que não ocorra o seu aniquilamento. Segundo as palavras de Van Gogh (1882/2020, p. 71): "suspeitam algo de mim - está no ar -, existe algo por trás de mim. Vincent esconde algo que não pode vir à luz".

As flores à mãe, 0 azul ao irmão. Na infância Vincent ensinava 0 irmão a patinar, a jogar bolinha de gude e tocar piano (Naifeh \& Smith, 2011). Na adultez Theo foi seu confidente, pai, irmão, financiador, curador das obras e admirador. 0 único que amava Vincent e o único da família que acreditava no seu talento (Maia, 2018). A potência desse encontro foi simbolizada pelo azul. 0 papel azul em uma parede que cobria um quartinho no sótão que os dois dividiam na infância (Naifeh \& Smith, 2011). Se as flores representavam a busca pelo materno, por uma perspectiva, a procura do azul poderia ser vinculada à tentativa de nutrir 0 absolutismo do vir-a-ser.

Continuo sempre à procura do azul. As figuras de camponeses, aqui, em regra geral, são azuis. No trigo maduro, ou destacando-se sobre as folhas secas de uma ala de faias, de forma que os matizes escalonados de azul-escuro e de azul-claro recobram vida e passam a expressar-se ... isto é muito bonito, e desde o começo me impressionou (Van Gogh, 1885/1991, p. 129).

Em correspondência para Theo, (Van Gogh, 1888/2020) disse que tinha começado a assinar as telas, mas que logo parou por achar que era uma grande besteira. Ele preferia assinar somente como Vincent e insistia para Theo divulgar dessa forma (Britto, 2018; dos Santos, 2018). Talvez 0 artista tenha feito isso como uma tentativa de rejeitar os pais na mesma medida em que foi rejeitado (Haziot, 2007). Quiçá como um esboço de independência para tentar desvincular metade do seu nome da lápide e deixar a outra metade vir-a-ser a partir dos tecidos de suas telas.

Entende-se que só resta para Vincent nutrir o que as figuras primordiais não nutriram. 0 pintar é a sua forma de colocar para dentro, de fazer o croqui, de esboçar o si-mesmo no espaço nulo.

0 que é que sou aos olhos da maioria - uma nulidade ou um homem excêntrico ou desagradável -, alguém que não tem uma situação na sociedade ou que não a terá; enfim, pouco menos que nada. Bom, suponha que seja exatamente assim, então eu gostaria de mostrar por minha obra o que existe no coração de tal excêntrico, de tal nulidade (Van Gogh, 1883/2020, p. 76).
Para ele, 0 alimento equivale à arte. "Prefiro não comer ao meio-dia durante seis meses, e assim fazer economias, do que receber de quando em vez dez florins"(Van Gogh, 1883/2020, p. 67). A arte é tão essencial para a sua sobrevivência psíquica que equivale à vida: "porque tenho da arte e da própria vida, de quem a arte é essência" (Van Gogh, 1883/2020, p. 77).

A única opção sempre foi dedicar a sua potência criativa não somente para a sua obra, mas para converter o croqui em pintura. Poucos meses antes de morrer, Vincent enviou uma carta ao irmão falando sobre a arte como possibilidade de pintar o si-mesmo. "Meu caro irmão — é sempre em meio ao trabalho que eu lhe escrevo —-, estou trabalhando como um verdadeiro possesso, mais que nunca estou num furor surdo de trabalho. E creio que isto contribuirá para minha cura" (Van Gogh, 1889/2020, p. 362).

\section{Considerações finais}

0 espaço da transicionalidade é inaugurado pela relação da díade mãe-bebê e possibilita as primeiras experiências culturais infantis (Neto, 2018; Serralha, 2019). Em conjunto com as variações desenvolvimentais da onipotência, esse locus viabiliza o exercício da criatividade de forma constitutiva. Segundo Winnicott (1975), o termo transicional faz referência a uma qualidade do uso objetal. Para a criança se adaptar de forma gradual ao mundo objetivo, há um objeto real que, apesar de ser externo, representa 0 estado interno e fusional com a mãe (Medeiros \& Passos, 2018).

Segundo Winnicott (1975), o termo transicional faz referência a uma qualidade do uso objetal. Para a criança se adaptar de forma gradual ao mundo objetivo, há um objeto real que, apesar de ser externo, representa 0 estado interno e fusional com a mãe (Medeiros \& Passos, 2018). 0 brincar atua justamente como uma forma de transitar e criar o interno-externo e 0 subjetivo-objetivo (Neto, 2018). Apesar de chegar na fase de independência, o brincar permanece como um continuum no espaço-tempo, pois 0 adulto continua brincando, mas em esferas diferentes, como arte, ciência e religião (Serralha, 2019).

Tendo em vista as características do ambiente em que Vincent viveu, é possível concluir que esteve exposto a falhas prematuras ambientais desde antes de nascer. Pode-se pensar que essas marcas mnêmicas intrusivas afetaram seu acesso à onipotência e, consequentemente, à capacidade criativa. Gestado na morte e a partir dela, Van Gogh dedicou todo o seu potencial criativo não somente para pintar suas obras, mas também para criar a própria existência. Suas criações pictóricas representavam a busca para converter a energia potencial do vir-a-ser em energia cinética. A partir do brincar com cores, Vincent expressou a sua subjetividade de forma a alargar e modificar a própria extensão do seu si-mesmo (Neto, 2018).

Entende-se que o tecido da tela atuou como tecido da pele. A arte possibilitou que 0 artista brincasse de forma (cri)ativa com os seus conflitos internos e externos - de forma que o Vincent verdadeiro fosse preservado e também buscado. A partir de suas telas, procurou expressar suas dores, mas também exercitar o seu potencial de vir-a-ser do croqui até ao pintar o si-mesmo. "Posso muito bem na vida e também na pintura me privar de Deus, mas não posso, privar-me de algo maior do que eu, que é minha vida, a potência de criar" (Van Gogh, 1888/2020, p. 257). 


\section{Referências}

Belo, F., \& Scodeler, K. (2013). A importância do brincar em Winnicotte Schiller. Tempo Psicanalítico, 45 (1), 91-101. Recuperado de: http://pepsic.bvsalud. org/scielo.php?script=sci_arttext\&pid=S0101-48382013000100007

Borges, H. (2017). Modulações do existir: entre luzes e sombras. Fractal: Revista de Psicologia, 29 (2), 191-195. Recuperado de: https://periodicos.uff.br/ fractal/article/view/5164/5018

Britto, L. E. M. de C. (2018). A vida, a obra e a morte de Vincent Willem van Gogh: uma interpelação à teoria do processo criativo em psicanálise (Tese de doutorado). Pontifícia Universidade Católica de Minas Gerais, Belo Horizonte, MG, Brasil.

Creswell, J.W. (2014). Investigação Qualitativa e Projeto de Pesquisa: Escolhendo entre Cinco Abordagens. Porto Alegre: Penso Editora.

Dos Santos, A. G. R. (2018). O amarelo que habito_Arte, ética e clínica_um olhar fenomenológico hermenêutico sobre a trajetória poética de Vincent Van Gogh (Tese de doutorado). Universidade Federal Fluminense, Niterói, RJ, Brasil. Recuperado de: http://slab.uff.br/wp-content/uploads/ sites/101/2021/06/2018_t_AnaGabrielaRebelodosSantos.pdf

Fulgencio, L. (2018). Os objetivos do tratamento psicanalítico para Freud e paraWinnicott. Estilos Da Clinica, 23(2), 344-361. Recuperado de: https:// www.revistas.usp.br/estic/article/view/139503

Galvan, G. B. (2013). O conceito de falso si-mesmo na teoria do amadurecimento pessoal de D. W. Winnicott (Tese de doutorado). Universidade de São Paulo, São Paulo, SP, Brasil. Recuperado de: https://www.teses.usp.br/teses/ disponiveis/47/47131/tde-17072013-092308/pt-br.php

Gil, A. C. (2019). Métodos e Técnicas de Pesquisa Social. São Paulo: Atlas.

Haziot, D. (2007). Van Gogh. Porto Alegre: L\&PM.

Leão, A. (2011). 0 uso do objeto na arte de elaborar traumas. Rabisco, 1, 6366. Recuperado de: http://www.revistarabisco.com.br/admin/uploads/ Revista_Rabisco_Volume_0_Numero_1.pdf

Maesso, M. C. (2017). 0 tempo do luto e o discurso do Outro. Ágora: Estudos Em Teoria Psicanalítica, 20,337-355. Recuperado de: https://www.scielo. br/j/agora/a/g8mKhDtBM6pMq8cM308gjYf

Maggi, N. R. (2020). A condição humana em situação de isolamento: um encontro com a finitude pessoal e a busca de criatividade. Estudos de Psicanálise, 53, 167-173. Recuperado de: http://pepsic.bvsalud.org/scielo. php? script=sci_arttext\&pid=S0100-34372020000100019

Maia, D. D. (2018). 0 retrato genial de Vicent: um processo de individuação. Self, 3(9). Recuperado de: https://self.ijusp.org.br/self/article/view/36

Medeiros, R. M. S. G. de, \& Passos, M. C. (2018). 0 embalo perdido e 0 ceramicar: a arte modelando o self. Estudos de Psicanálise, 49, 169-180. Recuperado de: http://www.cbp.org.br/n49a17.pdf

Naifeh, S. W., \& Smith, G. W. (2011). Van Gogh: The Life. New York: Random House Incorporated.

Neto, M. (2018). A moradia do artista (Dissertação de mestrado). Universidade Católica de Pernambuco. Recife, PE, Brasil. Recuperado de: http://tede2. unicap.br:8080/handle/tede/989

Paiva, J. A. V. de. (2020). Algumas considerações preliminares acerca dos conceitos de autoclivagem narcísica, em Ferenczi, e de intelecto cindido, em Winnicott (Dissertação de mestrado). Pontifícia Universidade Católica de São Paulo. São Paulo, SP, Brasil.

Riter, H. (2018). Automutilação na adolescência: o desamparo e as tentativas de existir. Revista de Psicoterapia Da Infância e Da Adolescência, 101-112. Recuperado de: http://www.bivipsi.org/wp-content/uploads/ ceapia-2018-27-12.pdf

Santos, E. (2019). Desdobramentos filosóficos a partir de Winnicott. Natureza Humana-Revista Internacional de Filosofia e Psicanálise, 21(2).Recuperado de: http://pepsic.bvsalud.org/pdf/nh/v21n2/v21n2a13.pdf
Serralha, C. A. (2019). 0 espaço potencial: da origem à evolução. Estilos Da Clinica, 24(1), 157-172. Recuperado de: https://dx.doi.org/10.11606/ issn.1981-1624.v24i1p157-172

Van Gogh, T. (1888-1990). The Complete Letters of Vincent van Gogh. Little, Brown \& Co.

Van Gogh, V. (1958). The Complete Letters of Vincent van Gogh. Boston: Little, Brown \& C.

Van Gogh, V. (1991). The Complete Letters of Vincent van Gogh. Boston: Little, Brown \& $C$.

Van Gogh, V. (2020). Cartas a Theo. Porto Alegre: L\&PM.

Winnicott, D. W. (1975). 0 brincar e a realidade. Rio de Janeiro: Imago.

Winnicott, D. W. (1993). A família e o desenvolvimento individual. São Paulo: Martins Fontes.

Winnicott, D. W. (2000). Da pediatria à psicanálise: obras escolhidas. Rio de Janeiro: Imago.

Winnicott, D. W. (2013). 0 ambiente e os processos de maturação: estudos sobre a teoria do desenvolvimento emocional. In 0 ambiente e os processos de maturação: estudos sobre a teoria do desenvolvimento emocional. Porto Alegre: Artmed.

Winnicott, D. W. (2020). O brincar e a realidade. São Paulo: Ubu Editora. 